\title{
Erratum
}

\section{Diastereoselective Epoxidation of Allylic Diols Derived from Baylis-Hillman Adducts}

Ricardo S. Porto, Mario L. A. A. Vasconcellos, Elizete Ventura, Fernando Coelho* Synthesis 2005, 2297.

The drawings for Figures 1 and 2 were inadvertently exchanged. The correct figures are shown below.

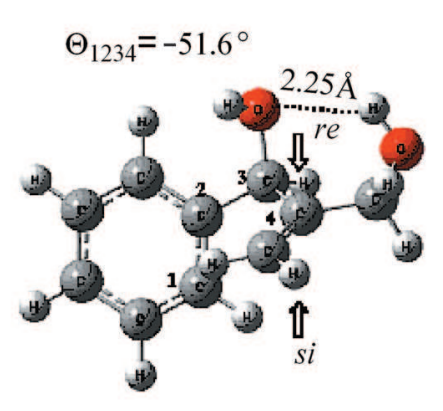

$\Delta \mathrm{H}=-61.29 \mathrm{kcal} / \mathrm{mol}$

25a

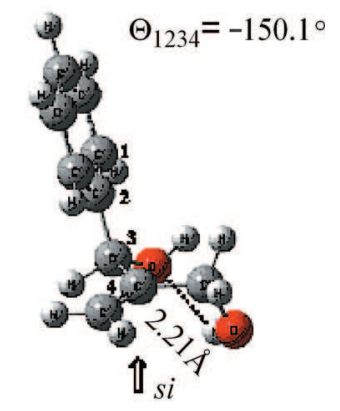

$\Delta \mathrm{H}=-61.42 \mathrm{kcal} / \mathrm{mol}$

25b

Figure 1 Minimal energy conformations for allylic diol 25

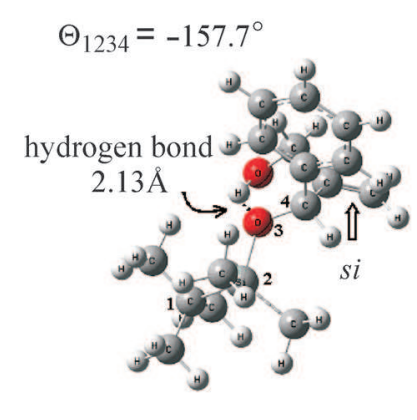

$17 \mathrm{a}$

$\Delta \mathrm{H}=-120.29 \mathrm{kcal} / \mathrm{mol}$

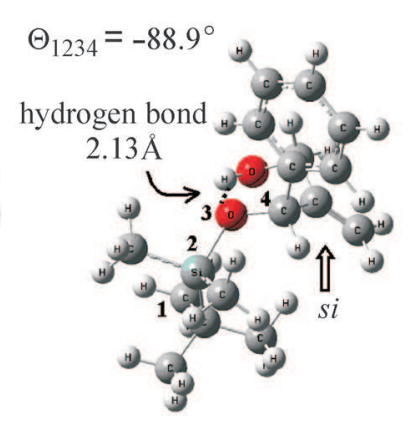

$17 \mathrm{~b}$

$\Delta \mathrm{H}=-120.18 \mathrm{kcal} / \mathrm{mol}$

Figure 2 Minimized conformations for the silylated allylic diol 17 